\title{
Yargıya yansıyan kalça kırığı vakalarının tıbbi ve hukuki değerlendirilmesi
}

\section{Medical and legal evaluation on hip fracture cases submitted to the court}

\author{
Serdar Şirazi ${ }^{1}$, İrfan Esenkaya ${ }^{2 *}$, İlhan Açıkgöz \\ 1Ortopedi ve Travmatoloji Uzmanı - Hukukçu - Arabulucu; Özel Avcılar Anadolu Hastanesi - \\ Şahin Avukatlık Bürosu - Akademi Arabuluculuk ve Tahkim Merkezi, İstanbul \\ ${ }^{2}$ Emekli öğretim üyesi, Ortopedi ve Travmatoloji Uzmanı, SANTE Tıp Merkezi, İstanbul \\ *Tıp Hukuku Yüksek Lisansı, MA \\ ${ }^{3}$ Ortopedi ve Travmatoloji Uzmanı - Avukat - Hastane Yöneticisi
}

\begin{abstract}
Yüksek enerjili travmaların ve ortalama yaşam ömrünün uzamasına bağlı olarak kalça kırıkları son zamanlarda daha sık görülmekte ve ortopedi ve travmatoloji hekimlerinin daha fazla karşılaşmalarına neden olmaktadır. Vaka sayılarının artması olası aksaklıkları da gündeme getirmekte, bu konuda ortopedi ve travmatoloji hekimleri istenmeyen davalar ile karşılaşabilmektedir. Yüksek yargı kararları incelendiğinde kalça kırıkları konusunda ortaya çıkan uyuşmazlıkların büyük bir kısmı ceza davası olarak ortaya çıkmaktadır. Makalemizde kalça kırıkları ile ilgili yargıya yansıyan birkaç dava örnek olarak verilmiş ve bu konularda alınabilecek tedbirler, ortopedi ve travmatoloji hekiminin tanı ve tedavide göstereceği dikkat ve özen yükümlülüğü, bu süreçte tutacağı kayıt ve belgeler üzerinde durularak olumsuzluk teşkil eden uyuşmazlıklarla karşılaşımaması hedeflenmiştir.
\end{abstract}

Anahtar sözcülkler: kalça kırı̆̆ı; komplikasyon; malpraktis; sağlık hukuku; tıp hukuku

\begin{abstract}
Hip fractures are frequent in all life periods due to increase in number and various types of high energy traumas and prolonged life expectancy, and more commonly encountered by surgeons of orthopedics and traumatology. This increased number of phenomena may provoke possible faults, and orthopedics and traumatology surgeons may encounter claims of complaints and lawsuits. The disputes against surgeons regarding hip fractures include compensation claims, criminal proceedings and lawsuits. In our article, examples are presented from cases submitted to the court and an interaction with preventive behavioural model is aimed to reduce disputes, emphasizing the possible precautions, liability of surgeons regarding their attention and care in diagnosis and treatment, and the records and documents that should be kept during this process.
\end{abstract}

Key words: hip fracture; complication; malpractice; health law; medical law
K alça kırıkları gerek yüksek enerjili travmaların artması gerekse ortalama yaşam ömrünün uzamasına bağlı olarak son zamanlarda daha sık görülmekte ve ortopedi ve travmatoloji hekimlerinin daha fazla karşılaşmalarına neden olmaktadır. Bu konuda vaka sayılarının artması olası aksaklıkları da gündeme getirmektedir. Bu konuda ortopedi ve travmatoloji hekimleri istenmeyen davalar ile karşılaşabilmekte ve hekimlerin motivasyonu da oldukça olumsuz etkilenebilmektedir. Makalemizde kalça kırıkları ile ilgili yargıya yansıyan davalardan örnekler verilmiştir.
Bu konularda alınabilecek tedbirler, ortopedi ve travmatoloji hekiminin tanı ve tedavide göstereceği dikkat ve özen yükümlülüğü, bu süreçte tutacağı kayıt ve belgeler üzerinde durularak uyuşmazlıklara yönelik olarak proaktif (sorun ortaya çıkmadan) bir etkileşim hedeflenmiştir. Böylece olumsuzluk teşkil eden uyuşmazlıklarla karşılaşılmaması amaçlanmıştır.

Yüksek yargı kararları incelendiğinde kalça kırıkları konusunda ortaya çıkan uyuşmazlıkların büyük bir kısmı şikâyet, savcılık soruşturması ve ceza davası süreçlerinin takip etmesi sebebiyle ceza davası olarak

- İletişim adresi: Dr. Serdar Şirazi, Akademi Arabuluculuk ve Tahkim Merkezi. Ofis Florya Plaza, Şenlikköy Mah. Eski Halkalı Cad. No: 3, K: 2, D: 25B. Florya, Bakırköy, İstanbul Tel: 0536 - 6811187 e-posta: drserdarsirazi@yahoo.com 
ortaya çıkmaktadır. Yani ilgili hekimin hareketinin suç niteliğinde olduğu iddiasıyla açılan davalardır. Makale özellikle ceza hukuku uygulamaları esas alınarak hazırlanmıştır.

\section{ÖRNEK DAVALAR}

\section{Örnek Dava 1}

Kalça kırı̆̆ı ile ilgili ilk örnek, Yargıtay 13. Hukuk Dairesi'nin verdiği bir kararla ilgilidir. ${ }^{[1]}$ Davacı geçirdiği kaza sonucu hastaneye başvurmuş ve film çekilerek yumuşak doku zedelenmesi teşhisi konularak istirahat etmesi gerektiği söylenmiş. İstirahatle ağrısının geçmemesi üzerine başka sağlık kuruluşuna başvurmuş ve kalça kırığı tanısıyla total kalça protezi operasyonu yapılmış. Davacı tanı eksikliğine bağlı iş gücü kaybı, zaman kaybı ve tedavinin güçleştiği iddiasıyla maddi ve manevi tazminat talebinde bulunmuş. Adli Tıp Kurumu raporunda kalça protezinin geç teşhis sebebiyle uygulandığına dair veya erken teşhis konsaydı kalça protezi yerine başka bir tedavi uygulanacağına dair bir ilişki kurulamadığını, tanı gecikmesi ile uygulanan tedavi arasında illiyet (nedensellik) bağı bulunmadığını mütalaa etmiş ve ilk derece mahkemesi davayı Adli Tıp Kurumu raporunu dikkate alarak reddetmiş. Ancak davacı hasta karara itiraz ederek üst mahkemeye başvurmuş. Üst mahkemenin yaptığı değerlendirme sırasında alınan Adli Tıp Kurumu raporunda, hastanın grafisinde kırığın belli olduğu ancak hastada çocuk felci olduğundan dolayı atlanabileceği, atlanmasının tedavi değişikliğine sebep olmadığı mütalaa edilmiş. Yargıtay 13. Hukuk Dairesi de mesleki tecrübesizlikten dolayı geç teşhisin sabit olduğu, dolayısıyla uzman hekim bilirkişilere dosyanın yeniden gönderilerek hekimin ve hastanenin vekâlet ve adam çalıştıranın borcu açısından tekrar değerlendirilerek karar verilmesi gerektiğine kanaat getirip dosyayı yerel mahkemeye göndermiş.

Söz konusu davada hastada muhtemel femur boyun kırığı mevcut olup eksik inceleme veya gerekli dikkat ve özen yükümlülüğü gösterilmeden tedavi verilmiş ve tanı atlanmış. Bu durumda her ne kadar Adli Tıp Kurumu geç teşhis ile uygulanan tedavi arasında bir illiyet bağının olmadığı yani erken dönemde de aynı tedavinin uygulanacağını belirtmiş olsa da, yüksek mahkeme bu değerlendirmeyi eksik görerek hekimin hukuki sorumluluğu üzerinde durmuş ve dosyanın bu açılardan daha geniş değerlendirmeye tabi tutulması için bilirkişi heyetine verilerek bir karara varılmasının gerektiğine karar vermiş.

Göz önünde bulundurulması gereken en önemli hususlardan birisi, hekimin muayene ve travmanın şiddetine göre en ufak bir şüphe duyması durumunda röntgen grafisine ek olarak bilgisayarlı tomografi (BT) hatta manyetik rezonans (MR) görüntüleme tetkiklerini istemesinin olası kırıkların atlanmasının önüne geçeceği durumudur. Bu şekilde hekim hukuki sorumluluklarından olan dikkat ve özen yükümlülügünü yerine getirmiş olacaktır. Ayrıca dikkat edilmesi gereken bir diğer husus, özellikle kalça kırığı gibi erken cerrahinin önemli olduğu olgularda, tanı gecikmesinin tedavi seçimini değiştireceği ve tedavi seçimine etki eden faktörlerin de uyuşmazlığın çözümü sırasında mahkemelerce sorgulanacağının bilinmesi gerektiğidir.

\section{Örnek Dava 2}

Bir diğer dava da ceza davası olarak karşımıza çıkmaktadır. Dava Yargıtay'ın Ceza Dairesi tarafından incelenen bir dosyadır. ${ }^{[2]}$ Davacı trafik kazası sonucu multitravma (çoklu travma) nedeniyle hastaneye başvurmuş ve distal femur kırı̆ğ tespit edilerek ameliyat edilmiş. Ameliyat sonrası çekilen kontrol grafisinde kalçada kırık olduğu saptanmış. Yani ilk başvurduğunda pelvis grafisinin çekilmemesi sonucunda femur intertrokanterik kırık tanısı konulamamış. Adli Tıp Kurumu 3. intisas Kurulu raporunda intertrokanterik kırığın tedavisinde gecikme olduğu belirtilmiş, ayrıca iki farklı üniversiteden öğretim görevlilerinden oluşan iki ayrı kurul oluşturularak tanı gecikmesinin iyileşme sürecine etkisi sorgulanmış. Üniversitelerden oluşturulan bilirkişi heyetleri Adli Tıp Kurumu'nun kararının aksine kırık tespitindeki bu gecikmenin hastanın diğer kırıklarının da göz önünde bulundurulmasıyla iyileşme sürecini geciktirmediği yönünde rapor vermiş. Adli Tıp Kurumu'nun verdiği rapor ile iki ayrı üniversite ögrretim üyelerinden oluşan kurulların verdiği raporlar arasındaki farklılıktan dolayı yüksek mahkeme çelişkinin giderilmesi için günümüzde bilirkişi statüsü kaldırılan ancak o dönemde ceza yargılamalarında başvurulması zorunlu olan Yüksek Sağlık Şurası'ndan rapor tanzim edilmesi gerektiğine kanaat getirerek yerel mahkemenin hekim lehine verdiği beraat kararını bozmuş.

Söz konusu davada hekimin multitravmalı hastada değerlendirilmesi gereken pelvisi değerlendirmemesi suretiyle tanıyı atlaması görevi ihmal suçu kapsamında değerlendirilmiş ve hareketin suç özelliğinden dolayı ceza davası açılmış.

Ortopedi ve travmatoloji hekimlerinin kesin olarak bildiği ancak uygulamada zaman zaman ihmal edilen ayrıntılı sistemik fizik muayeneye ilaveten istenecek radyolojik tetkiklerde kırığın bulunduğu yerin bir üst bir alt eklemini de içerecek şekilde görüntülenmesi bu konularda yaşanabilecek olumsuzlukların önüne geçilmesini sağlayacaktır. 


\section{Örnek Dava 3}

Dava ameliyat sırasında oluşan ve ortopedi ve travmatoloji hekimi tarafından da fark edilip hastaya da bilgi verildiği savunması ileri sürülen periprostetik (protez çevresi) kırığa dair bir kaydın ameliyat notunda tespit edilememesi ve ilk derece mahkemesi tarafından ilgili hekime periprostetik kırık nedeniyle taksirle yaralama suçundan mahkumiyet kararı verilmesini konu almaktadır. Davalı, yani ortopedi ve travmatoloji uzmanı karara itiraz ederek istinafa başvurmuş. Yargıtay Ceza Dairesi[ ${ }^{3]}$ kararı onamış, yani hekime verilen mahkûmiyet kararı kesinleşmiş. Ancak çoğunluğun görüşüne katılmayan üyelerin verdiği muhalefet şerhinin burada dikkatle değerlendirilmesi önem arz etmektedir.

Şerhi koyduran Yargıtay'ın ilgili dairesinin hâkim üyeleri eksik kovuşturma olduğunu öne sürmüşler. Şerhte; düşme nedeniyle eğitim araştırma hastanesi aciline götürülen 1940 doğumlu hastada femur boyun kırı̆̆ının tespit edildiği, bipolar hemiartroplasti operasyonu yapıldığı ve postop (ameliyat sonrası) takip amaçlı yoğun bakım ünitesine alındığı, takiplerinde sorun yaşanmaması üzerine 3 gün sonra taburcu olduğu, yaklaşık 2 yıl sonra sanık olan ortopedi ve travmatoloji uzmanının çalıştı̆̆ı özel bir hastaneye müracaat edildiği belirtilmiş. Yapılan muayenede protezde gevşeme tespit edilerek kan tetkiki ve sintigrafi sonucu gevşemenin aseptik olduğu saptanmış. Hastaya davalı ortopedi ve travmatoloji uzmanı tarafindan çimentosuz revizyon total kalça protezi operasyonu yapılmış. Taburcu edildikten 1 hafta sonra sol kalça ağrısı nedeniyle başvuran hastanın femoral stemin distale migre olduğu görülerek 2. revizyon operasyonu çimentolu femoral stem konularak yapılmış. Taburcu edildikten 2 gün sonra tekrar ağrısı olan hasta bu sefer başka bir özel hastaneye başvurmuş ve uzun femoral stem kullanılarak 3. revizyon operasyonu yapılmış. Adli Tıp Kurumu 3. Ihtisas Kurulu raporunda hastanın ikinci revizyon operasyonunda yani çimentolu femoral stem konulan ameliyatta periprostetik kırık geliştiği, bunun meydana gelebilecek bir komplikasyon olduğu, önlem alınması gerektiği ve hekim tarafından fark edilip edilmediğinin kayıtlarda bulunmadığı, ilgili ortopedi ve travmatoloji hekiminin eyleminin tıp kurallarına uygun olmadığını mütalaa etmiş. Ancak sanık olan hekim savunmasında operasyon sırasında çekilen grafilerde kırığı tespit ettiğini ve bu hususta hasta ve yakınlarına bilgi verdiğini, fakat hastanın ve yakınlarının başka bir merkezde ameliyat olmak istediklerini beyan ettiklerini söylemiş. Muhalefet şerhi koyduran hâkimler, hekimin verdiği bu savunmanın hastanın oğlu tarafından da kısmen doğrulandığını, dolayısıyla bu sebeplerden dolayı dosyanın Adli Tıp Kurumu Genel Kurulu'na gönderilerek sanık tarafından yapılan tüm operasyon süreçlerinin değerlendirilmesi gerektiğini, ancak bu sayede hekimin tıp kurallarına uymayan davranışının bulunup bulunmadığı yönünde karar verilebileceğini, dolayısıyla çoğunluğun hekim aleyhine verilen mahkûmiyet kararına katılmadıklarını belirtmişler.

Söz konusu davada üzerinde durulması gereken durumlardan birisi perop (ameliyat sırasında) gelişen komplikasyon olan periprostetik kırık hadisesidir.

Komplikasyon yönetiminde en önemli husus, hastayı gelişen yeni durum hakkında bilgilendirmek, uygulanacak yeni tedavi politikası (süreci) için onam almak ve komplikasyonu da, aydınlatmayı da, onamı da kayıtlara almaktır. Örnekteki periprostetik kırı̆ı̆n ameliyat notunda kayıt altına alınmamış olması, hekimin ihmal ile suçlanmasına sebep olmuştur. Hekimin komplikasyon geliştiğinde ne yaptığını ameliyat raporunda belirtmesi durumunda Adli Tıp Kurumu'nun vereceği raporun içeriği de değişebilecektir. Çünkü Adli Tıp Kurumu dosya üzerinden değerlendirme yapmaktadır. Ayrıca hekim, hasta ve yakınlarının başka bir merkezde tedavilerine devam etme isteklerini de tedaviyi ret formu ile kayıt altına almamıştır. Periprostetik kırığın ameliyat notuna kayıtlanmış olması, önerilen yeni ameliyatın kayıtlara işlenmiş olması ve hastanın başka hastaneye gitme sebebinin de tedaviyi ret formuna kayıtlanmış olması, bu vakada hekimi sorumluluktan kurtaracak davranış modeli olarak karşımıza çıkmaktadır. Keza hekimin durumu belgelerle ispatlamış olması halinde yaptığı girişim sonucu gelişen komplikasyon durumunda sürecin doğru yönetildiğini göstermesi açısından oldukça önemlidir. Söz konusu davada hekim tutulacak kayıtlarla gelişen komplikasyon karşısında ceza almaktan kolaylıkla kurtulabilecekken, ne yazık ki mahkûmiyet kararı çıkmıştır.

\section{Örnek Dava 4}

İncelenecek diğer bir olgu, kamu görevlisinin resmi belgede sahtecilik eylemlerinin olduğu iddiasına dair açılmış bir davayı konu almaktadır. ${ }^{[4]}$ Kalça kırığı ameliyatlarında kullanılan protez hastaneye fatura edilmiş ve ilgili hekim "kullanıldı" belgesini imzalamış. Ancak hastaya kullanılan protez ile belgede ismi geçen protezin farklı olmasından dolayı konu savcılığa intikal ettirilmiş. Yapılan soruşturma sonucunda ortopedi ve travmatoloji hekimine kamu görevlisi tarafından resmi belgede sahtecilik suçu atfedilerek iddianame hazırlanarak ceza davası açılmış. Yargılama sırasında yapılan değerlendirmede ameliyattan önce asistan doktorlar tarafindan protezin steril halde medikal firmadan istendiği, ameliyattan sonra medikal firmanın protez bedellerini alabilmek için reçete, gereklilik ve kullanım raporlarının 
topluca hekimlere imzalatıldığı saptanmış. Ayrıca hastalara kullanılan protezler ile imzalatılan belgelerde adı geçen protezlerin birbirleri ile neredeyse aynı olacak şekilde benzerlik göstermeleri, kalite bakımından muadil olmaları ve fiyatları arasında fark olmaması, Sosyal Güvenlik Kurumu'nun belgede belirtilen protezlerin de ameliyatlarda kullanılabileceğine ilişkin anlaşmalarının olması, belgelerde imzası olan hekimlerin bu ameliyatlara girmeyip imza atmaları, ameliyat raporlarında ve dosyalarda hastalara kullanılan protezlerin gerçek isminin yazıldığı ve barkodlarının yapıştırıldığı, sanık hekimlerin medikal firmasınca düzenlenen belgeleri güven ilişkisine dayanılarak imzalamaları, hekimlerin zarar verme bilinç ve iradeleri ve sahtecilik kastıyla hareket ettiklerinin söylenemeyeceğine Yargıtay'ın ilgili dairesince kanaat getirilmiş. Ancak gerekli özen ve dikkati göstermeyip ameliyat raporları ve dosyalarını kontrol etmeden medikal firma yetkilisinin ameliyat sonrası düzenlediği belgeleri gerekli denetimi yapmadan imzalayıp onaylamasının görevi ihmal suçunu oluşturduğu sonucuna varmıştır.

Operasyonlardan sonra çalışılan kurumun idari yapısına bağlı değişkenlik gösteren hangi malzemelerin kullanıldığına dair tutulan raporların ameliyat raporları ve hastanın dosyasında yapıştırılmış ve belirtilmiş halde bulunan barkodlar ile birlikte kontrol edilerek hazırlanması gerektiğine dair iyi bir örnek teşkil etmektedir. Yapılan değerlendirmede hekimin resmi belgede sahtecilik suçunu işlemediği ancak gereken dikkati göstermemesinden dolayı görevi ihmal suçunu işlediğine kanaat getirilerek bu suçtan mahkûmiyet kararı verilmiştir.

\section{Örnek Dava 5}

Bir diğer dava örneği de Yargıtay 13. Hukuk Dairesi'nin vermiş olduğu bir karardır. ${ }^{[5]}$ Davacı geçirdiği trafik kazası sonucu başvurduğu hastanede femurda parçalı kırık tanısı konulduğunu, ertesi gün gecikmeli olarak ameliyat edildiğini, taburcu olacağı gün yatağında doğrulacağı zaman vücudundan ses geldiğini, kalçasında kırık tespit edildiğini, kırığın ameliyat sırasında konulan implanttan kaynaklandığını iddia etmiş. Mahkeme dosyada bulunan Adli Tıp Kurumu'nun raporunu dikkate alarak davayı reddetmiş, ancak davacılar temyiz başvurusunda bulunmuş. Adli Tıp Kurumu'nun raporu incelendiğinde genel beden travması ile hastaneye getirilen hastanın femur kırığı ile birlikte femur boyun kırı̆ı̆ın da bulunduğu, femur boyun kırıklarının ilk değerlendirmede teşhis edilemeyebilece$\breve{g i}$, bu durumun kişinin durumundan ve kırı̆gın niteliklerinden kaynaklandığı, gelişen bu durumun ameliyat sonunda fark edilip, gerekli ek tedavisinin önerilmesi, son yapılan muayenesinde femur şaft (cisim) kırığında gelişen psödoartroz (kaynamama) komplikasyonu nedeni ile defalarca geçirdiği ameliyatlara rağmen minimal sekelle (en az hasarla) iyileşmesi göz önüne alındığında hekimlere atfedilebilecek kusur tespit edilmediği mütalaa edilmiştir. Yargıtay sonraki operasyonların ilk operasyonun hatasından kaynaklanıp kaynaklanmadığı hususunun Adli Tıp Kurumu raporu ile tam olarak aydınlatılmadığı gerekçesiyle 3 kişilik uzman bilirkişi heyeti oluşturulup konunun detaylı incelenmesi gerektiği yönünde karar vermiştir.

Söz konusu davada iki hadise söz konusudur. Birincisi femur şaft (cisim) operasyonu sonrası psödoartroz gelişmesi, diğeri de femur boyun kırı̆̆ının tespit edilememesidir. Femur boyun kırıklarının X-ray grafide tespit edilememesine diğer dava örneklerinde de belirtildiği gibi rastlanabilmektedir. Bu durum kalçaya yapılacak ileri radyolojik görüntüleme teknikleri ile aşılabilecektir. Ayrıca kırıklardan sonra kaynamama ve diğer komplikasyonların gelişebileceği ve bu durumda ek tedavilere ihtiyaç olabileceği konusu da hastaya açıklanmalı ve hastanın bu konuda bilgi sahibi olması sağlanmalıdır.

\section{Örnek Dava 6}

Yine Yargitay Ceza Genel Kurulu[ ${ }^{[6]}$ tarafindan verilen bir kararda; trafik kazası nedeniyle hastaneye getirilen 1920 doğumlu hastada çok sayıda kaburga kırıkları, kalça kemiği kırığı, kafatası kırığı, köprücük kemiği kırığı tanılarının olduğu ve hayati tehlikesi yoktur denilerek 5 saat müşahede altında tutulduktan sonra evine gönderilmesini konu almaktadır. Kazazede aynı gün evde fenalaşarak tekrar hastaneye gelmiş ancak hastanede yapılan müdahalelere rağmen vefat etmesi sonucunda yakınları tarafından dava açılmış. Dosyada bulunan Adli Tıp Kurumu 1. İhtisas Kurulu'nun raporunda multipl (çoklu) kot kırığı, sağ klavikula kırığı, sol pnömotoraks cilt altı amfizemi, sağ ramus pubis superior ve inferior kırı̆ıı olduğu, kırıkların tespit edilememesinde eksiklik olduğu, ancak kişide tespit edilen travmatik değişimlerin ağılıkları ve kişinin yaşı da dikkate alındığında zamanında tespit edilerek uygun tedavisinin başlanması durumunda da kişinin kurtarılmasının kesin olmadığını belirttiği, hastanın çoklu kırık ve iç organ yaralanması sonucu gelişen komplikasyonlara bağlı öldüğü, dolayısıyla hekimin eylemi ile netice arasında illiyet bağının kesin bir şekilde kurulamadığı, bu nedenden dolayı taksirle öldürme suçundan sorumlu tutulamayacağı belirtilmiş.

Yüksek Sağlık Şurası'nın raporunda; sanık hekimin multitravmalı hastaya yaklaşımının hatalı olduğu, kırıkları tespit edemediği, ağır travmaya rağmen sevk etmediği, hastayı multidisipliner (çok alanlı) 
değerlendiremediği, tıbbın gereklerini yapmadığından dolayı kusurlu olduğu, genel beden travmasına ve çoklu kemik kırıklarına maruz kalmış öleni stabilizasyonu sağlanıncaya kadar ve tıp çevrelerinde genel olarak kabul gördüğü şekilde 24 saat müşahede altında tutması veya başka bir sağlık kuruluşuna sevk etmesi gerekirken, 5 saat sonunda taburcu ederek evine göndermesi sonucunda taburcu etmesi ile TCK 85/1 kapsamında taksirle bir kişinin ölümüne neden olma suçunu değil, TCK 257/2 maddesi gereği görevi ihmal suçunu oluşturduğuna kanaat getirilmiş.

\section{Örnek Dava 7}

Yargıtay 12. Ceza Dairesi'nin ${ }^{[7]}$ verdiği bir kararda yüksekten düşme nedeniyle gece saat 21.00 sularında devlet hastanesine acile getirilen hastada sol önkol açık kırık, pelvis ve femur kırığı tespit edilmiş ve icapçı ortopedi ve travmatoloji hekimine haber verilmiş. Ortopedi ve travmatoloji hekimi hastaneye gelmeyerek hastanın üst merkeze sevk edilmesini söylemiş ve hasta eğitim araştırma hastanesine yakınları olmadığı için radyoloji teknisyeninin refakatinde sevk edilmiş. Eğitim ve araştırma hastanesinden tedavisinin ilgili devlet hastanesinde devam edilebileceği söylenerek ambulansla tekrar ilk başvurduğu hastaneye yönlendirilmiş. Tekrar devlet hastanesi acil hekimi tarafından ortopedi ve travmatoloji hekimi aranmış ve hastanın müşahedede tutulmasını ve sabah saatlerinde tarafınca değerlendirileceği belirtilmiş. Hastanın müşahede odasında vitallerinin (hayati bulgularının) bozulması ve sonrasında 08.10 'da vefat etmesi sonucunda önce savcılık soruşturması, akabinde de ceza davası açılmış.

Adli Tıp Kurumu ihtisas Dairesi ve Yüksek Sağlık Şurası tarafından düzenlenen raporlarda ortopedi ve travmatoloji konsültasyonu istenmesine rağmen ilgili hekimin muayene etmek için gelmemesinin tıbbi uygulamada eksiklik olduğu, dolayısıyla hekimin kusurunun bulunduğu, ölüm ile hekimin eylemi arasında illiyet bağının kesin bir şekilde kurulamadığı, dolayısıyla sanığın taksirle öldürme suçundan sorumlu tutulamayacağı, görevinin gereklerini yapmakta ihmal veya gecikme gösterme fiili kapsamında değerlendirilmesi gerektiği mütalaa edilmiştir.

Söz konusu olayda hekimin çalıştığı kurumun kamu veya özel olmasından bağımsız olarak konsültasyon taleplerine zamanında ve uygun olarak cevap vermesi gerektiği, aksi takdirde görevini ihmal suçu sayılacağı görülmektedir. Hatta bu ihmalin hastanın ölümüne veya sakat kalmasına neden olması halinde nedensellik bağının kurulması durumunda daha farklı ve ağır cezalarla karşılaşılabileceği göz önünde bulundurulmalıdır. Uzaktan yapılan değerlendirmelerde hekimin en çok dikkat etmesi gereken konu, hastanın travma öyküsünün niteliği ve olası tıbbi durumları değerlendirmek olmalıdır. Olası tıbbi durumlar uzaktan değerlendirilemiyor yahut ufak da olsa şüphe kalıyorsa hekim icaba bizzat katılmalı, gerekli sistemik değerlendirmelerini yapmalıdır.

\section{Örnek Dava 8}

Bu konuda ele alınacak son dosya Yargıtay 5. Ceza Dairesi tarafindan verilmiş bir kararla ilgilidir. ${ }^{[8]}$ Trafik kazası sonucu devlet hastanesine kaldırılan hastanın ortopedi ve travmatoloji hekimi tarafindan yapılan değerlendirme sonucunda femur intertrokanterik kırığı teşhis edilememiş. Hasta taburcu olduktan sonra ağrılarının devam etmesi sonucunda bu defa üniversite hastanesine başvurmuş ve femur intertrokanterik kırığı tanısıyla ameliyat edilmiş. Devlet hastanesinde teşhisinin konulamaması üzerine savcılık soruşturması sonrasında da ilgili ortopedi ve travmatoloji uzmanına ceza davası açılmış. Adli Tıp Kurumu'nun vermiş olduğu rapora göre pelvis filminin çekilmemesi sonucunda kalça kırığının tespit edilemediği, söz konusu filmin çekilmemesinin tıp kurallarına uygun olmadığı ve ihmal suretiyle görevi kötüye kullanma suçunun kasıtla işlendiğine kanaat getirilmiş.

Kalça kırıkları gerek tanıda yaşanabilecek problemler gerekse tedavi sonrası gelişebilecek komplikasyonlar açısından ortopedi ve travmatoloji pratiğinde oldukça fazla yer almaktadır ve giderek daha fazla alacağı öngörülmektedir.

Ortopedi ve travmatoloji hekiminin tanı ve tedavide göstereceği dikkat ve özen yükümlülügüü, bu süreçte tutacağı kayıt ve belgeler sayesinde ileride istenmeyen davaların açılmasına engel olacaktır.

\section{KAYNAKLAR}

1. T.C. Yargıtay On üçüncü Hukuk Dairesi Esas: 2014/10929, Karar: 2014/34504 Tarih: 05.11.2014. https://www.corpus. com.tr

2. T.C. Yargıtay On ikinci Ceza Dairesi Esas: 2014/6729, Karar: 2014/10003 Tarih: 24.04.2014. https://www.corpus.com.tr

3. T.C. Yargıtay On ikinci Ceza Dairesi Esas: 2016/2176, Karar: 2016/9149 Tarih: 31.05.2016. https://www.corpus.com.tr

4. T.C. Yargıtay On birinci Ceza Dairesi Esas: 2014/13026 Karar: 2014/20135 Tarih: 25.11.2014. https://www.corpus.com.tr

5. T.C. Yargıtay On üçüncü Hukuk Dairesi Esas: 2014/20386 Karar: 2015/11386 Tarih: 09.04.2015. https://www.corpus. com.tr

6. T.C. Yargitay Ceza Genel Kurulu Esas: 2017/12-271 Karar: 2017/278 Tarih: 16.05.2017. https://www.corpus.com.tr

7. T.C. Yargıtay On ikinci Ceza Dairesi Esas: 2017/6800 Karar: 2019/4748 Tarih: 09.04.2019. https://www.corpus.com.tr

8. T.C. Yargıtay Beşinci Ceza Dairesi Esas: 2012/11042 Karar: 2014/1038 Tarih: 30.01.2014. https://www.corpus.com.tr 